NBER WORKING PAPER SERIES

EXPOSURE TO A SCHOOL SHOOTING AND SUBSEQUENT WELL-BEING

Phillip B. Levine

Robin McKnight

Working Paper 28307

http://www.nber.org/papers/w28307

NATIONAL BUREAU OF ECONOMIC RESEARCH

1050 Massachusetts Avenue

Cambridge, MA 02138

December 2020

We are grateful to seminar participants at Wellesley College and at the National Bureau of Economic Research Summer Institute Children's Program Meeting for helpful comments. Tom Downes also provided useful advice regarding the use of the NCES Common Core of Data. The views expressed herein are those of the authors and do not necessarily reflect the views of the National Bureau of Economic Research.

NBER working papers are circulated for discussion and comment purposes. They have not been peer-reviewed or been subject to the review by the NBER Board of Directors that accompanies official NBER publications.

(C) 2020 by Phillip B. Levine and Robin McKnight. All rights reserved. Short sections of text, not to exceed two paragraphs, may be quoted without explicit permission provided that full credit, including $\odot$ notice, is given to the source. 
Exposure to a School Shooting and Subsequent Well-Being

Phillip B. Levine and Robin McKnight

NBER Working Paper No. 28307

December 2020

JEL No. I18,I21

\begin{abstract}
$\underline{\text { ABSTRACT }}$
This paper examines the impact of school shootings on the educational performance and longterm health consequences of students who survive them, highlighting the impact of indiscriminate, high-fatality incidents. Initially, we focus on test scores in the years following a shooting. We also examine whether exposure to a shooting affects chronic absenteeism, which may play a role in explaining any such effect, and school expenditures, which may counteract it. We analyze national, school-district level data and additional school-level data from Connecticut in this part of the analysis. In terms of effects on health status, we focus on its most extreme measure, mortality in the years following a shooting. In this part of the analysis, we analyze county-level data on mortality by cause. In all analyses, we treat the timing of these events as random, enabling us to identify causal effects. Our results indicate that indiscriminate, highfatality school shootings, such as those that occurred at Sandy Hook and Columbine, have considerable adverse effects on students exposed to them. We cannot rule out substantive effects of other types of shootings with fewer or no fatalities.
\end{abstract}

\author{
Phillip B. Levine \\ Department of Economics \\ Wellesley College \\ 106 Central Street \\ Wellesley, MA 02481 \\ and NBER \\ plevine@wellesley.edu \\ Robin McKnight \\ Department of Economics \\ Wellesley College \\ 106 Central Street \\ Wellesley, MA 02481 \\ and NBER \\ rmcknigh@wellesley.edu
}


Between 1995 and 2019, 302 people have died in 176 shooting incidents that occurred in public schools during school hours and caused at least one death. The tragedy and horror associated with these shootings is difficult to express. The media coverage of these events naturally focuses on those whose lives have been taken and the intense pain felt by their families and communities.

Of course, the impact may not end there. Every student enrolled in a school experiencing a shooting suffers trauma that has the potential to affect their lives subsequently. In the 20 years following the 1999 shooting at Columbine High School, we estimate that 180,000 students were exposed to a school shooting that occurred during school hours and caused at least one fatality (Levine and McKnight, 2020). The psychological distress that those students suffer may have a disruptive effect on many aspects of their lives following the event.

The purpose of this paper is to examine the longer-term well-being of the students who are exposed to a school shooting, focusing specifically on educational and health-related outcomes. We treat each shooting as an event whose timing is random. Our main empirical approach is a triple-difference estimation strategy; students in affected birth cohorts in relevant years in the locations of the shootings would experience differential outcomes if the shootings had a causal impact. As we document below, boys are more likely to be the victims of these shootings, so we consider the impact on boys and girls separately in much of our analysis. Because our overall empirical results are driven by indiscriminate, high-victimization incidents, we devote additional attention to the impact of two of the most egregious examples of such tragedies: the shootings at Sandy Hook Elementary, in Newtown, CT in 2012 and at Columbine High School, in Littleton, CO in 1999. ${ }^{1}$

\footnotetext{
1 The 2018 shooting at Marjorie Stoneman Douglas High School in Parkland, FL occurred too recently to examine given limitations on available data.
} 
We initially examine how survivors fare in school, focusing on standardized test scores in the years following the shooting. In this part of the analysis, we focus on shootings that took place at an elementary or middle school, which are less common. We do so because these tests are required annually in grades 3 through 8 and our national source of test score data restricts its attention to standardized tests given in these grades. National data are reported at the district level. We find that test scores fell considerably among affected students in the district where the Sandy Hook school shooting occurred, particularly for boys. We do not find a statistically significant impact across all shootings, which may reflect low statistical power, arising from relatively fewer shootings at elementary and middle schools and our use of data that are aggregated to the district level.

To provide additional context for the estimated impact at Sandy Hook, we examine test results from the state of Connecticut. These data are publicly reported at the school level. We find reductions in a measure of proficiency rates across the entire district following the shooting. These Connecticut data also enable us to examine a plausible mechanism for some of the test score results: chronic absenteeism (absence for more than 10 percent of school days). We find that the rate of chronic absenteeism at Sandy Hook Elementary more than doubled in the year after the shooting. It also increased at other elementary schools in the district, although to a lesser extent.

School shootings have financial implications for districts, which may try to lessen the impact on the surviving students by providing them with greater resources. To examine this issue, we use national, district-level financial data. We find that all types of school shootings lead districts to spend more money on "support services" (which includes counseling and security, but may also represent other services). In shootings classified as indiscriminate with multiple 
fatalities (like Sandy Hook), all forms of spending increase after the shooting, including instructional spending and a large increase in spending on support services. Based on our findings on test score results, though, this additional spending appears to be insufficient to offset the impacts on the exposed students.

We also explore the impact of shootings on longer-term health status, focusing on its most extreme - but objective - measure, mortality in the years following the shooting. We use county-level, Vital Statistics Mortality data with detailed causes of death between 1995 and 2017 to determine whether exposure to a school shooting affects life expectancy for some affected students in the years following a shooting. We use a similar triple-difference estimation strategy, also making use of the specific causes of death available in these data. If there is any causal effect of school shootings among young adults, it would arise in the form of additional deaths from "external" causes, including suicide and other accidents (which include "accidental poisonings," like drug overdoses), but not “internal” causes (cancer, heart disease, etc.). This analysis focuses on shootings that affected high-school aged children (14 to 18) at the time of the event.

We find that exposure to a school shooting may affect even this very extreme measure of health status. Again, though, we track a major contributing factor of the impact to indiscriminate shootings with numerous fatalities; Columbine is the most salient example in these data. External, but not internal, deaths increased as a result, particularly for boys. The fact that our data are aggregated to the county level, which may include multiple schools, makes it more difficult to identify the impact of shootings that were less extreme.

Taken together, our findings indicate long-term consequences - including lower test scores, increased absenteeism, and increased subsequent mortality - for those students, and 
particularly boys, who are exposed to the highest-victimization school shootings. We show that these negative outcomes occur despite substantially increased spending in affected school districts.

Our findings imply that the social costs of school shootings persist long after the shooting itself, affecting outcomes for exposed students through young adulthood and possibly beyond. As costly as the loss of life associated with such an event is, even that cost is an understatement of the amount of harm that is done.

\section{Prior Research}

Our analysis contributes to the literature on the impact of traumatic events on subsequent outcomes for those who were exposed. Past research has shown that exposure to such events has a harmful effect on mental health, as reviewed by Wilson (2017). The Oklahoma City bombing in 1995 is an example of such an event; North et al. (2001) find that 34 percent of survivors experienced post-traumatic stress disorder (PTSD). Lowe and Galea (2017) draw similar conclusions regarding exposure to mass shootings based on their review of the evidence. ${ }^{2}$ North, et al. (1994) provide an example of this research. They find that 28 percent of the survivors of a 1991 mass shooting in a cafeteria in Killeen, Texas, where 23 people were killed, met the criteria for PTSD following this event. In a recent contribution to this literature, Bharadwaj, et al. (2020) report that children who survived a 2011 mass shooting at a summer camp in Utøya, Norway, where 69 people were killed, experienced a 400 percent increase in mental health diagnoses following the shooting relative to a matched sample.

\footnotetext{
${ }^{2}$ Mass shootings are generally defined as shootings with four or more fatalities. While some school shootings meet this definition of a mass shooting, there are many school shootings that do not because they have three or fewer fatalities. Likewise, many mass shootings are not considered school shootings, because they do not occur on school grounds.
} 
Prior research has also documented that stressful and traumatic experiences hinder educational performance. This includes exposure to police violence (Ang, forthcoming), local homicides (Sharkey, 2010), and the short-run effects of Hurricanes Katrina and Rita (Sacerdote, 2012). ${ }^{3}$ The previously described summer camp shooting in Norway led to half a standard deviation decline in test scores among survivors (Bharadwaj, et al., 2020).

Our understanding of the long-term health consequences of such traumatic events is more limited. For instance, in their review of the evidence on the impact of mass shootings, Lowe and Galea (2017) conclude that "further reviews could also apply broader inclusion criteria, for example, to provide insight into the influence of direct and indirect exposure to mass shootings on other domains of functioning (e.g., physical health and social functioning).” Some research does find an impact, though. Dursun (2019) demonstrates that pregnant women exposed to mass shootings are more likely to give birth prematurely and to very low birth weight babies.

A school shooting represents another form of traumatic event that has the potential to affect survivors in its immediate aftermath and beyond. Following the school shooting at Columbine, for instance, an increased share of students reported, in a national survey, that they felt "too unsafe to go to school” (Brener, et al. 2002). Rossin-Slater, et al. (2019) find that exposure to a fatal school shooting increases anti-depressant prescriptions filled at retail pharmacies by 21 percent among youths under the age of 20. Elevated sales persist throughout the two-year post-shooting sample period, suggesting prolonged mental health consequences for survivors.

Recent research has explored the impact of exposure to a school shooting on other outcomes. Beland and Kim (2016) address educational outcomes. They find that math proficiency at

\footnotetext{
${ }^{3}$ In the long-run, test scores of students who moved to higher-performing school districts after the hurricanes actually improved.
} 
schools that experienced a fatal shooting is reduced by about 5 percentage points relative to unaffected schools in the same town, while English proficiency is reduced by about 4 percentage points, with larger effects in schools that experienced multiple fatalities.

Contemporaneous work by Cabral, et al. (2020) examines the longer-term impact on students who were exposed to shootings at 33 schools in the state of Texas. They find that survivors suffered lower levels of educational attainment, higher levels of absenteeism, and lower subsequent early career earnings. Their analysis is complementary to our own. While our strongest evidence comes from indiscriminate shootings with multiple fatalities, their data set does not include such events. But, while we lack statistical power to definitively identify the impacts of lower-victimization events, they have more power and conclude that these events are consequential for educational and economic outcomes.

\section{Documenting School Shootings}

Our key independent variable of interest is a measure of exposure to a school shooting. This measure is constructed from the comprehensive K-12 School Shooting Database created by the Center for Homeland Defense and Security (CHDS) at the Naval Postgraduate School. These data are intended to catalog "each and every instance a gun is brandished on school property for any reason, regardless of the number of victims (including zero), time, day of week, or category (e.g. planned attack, accidental, domestic violence, gang-related)” (Riedman and O’Neill, 2018). The database provides extensive information regarding each shooting, but we primarily rely on information about the school location, the number of fatalities, the time and day that the shooting occurred, and the category of shooting. CHDS separates the shootings into 19 categories, such as indiscriminate, accidental discharge of a firearm, bullying, gang-related shootings, self-defense, and others. We describe these data in greater detail in Levine and McKnight (2020). 
We limit our analysis to shootings that occur at a public school, on a school day and during school hours, when students are likely to be exposed to them. We also limit our analysis to shootings that resulted in a fatality. As documented in Levine and McKnight (2020), shootings with no fatalities appear to be subject to differential rates of reporting in the news media - and therefore differential likelihood of inclusion in the database - based on the timing and location of the shootings. Specifically, we show that shootings with no fatalities are more likely to be reported in the aftermath of a high-victimization shooting, when school shootings are a focus of public discussion. And shootings with no fatalities are more likely to be reported in urban than in rural areas, a pattern that may be attributable to greater presence of local media. Regardless of the reason for the bias in reporting, we conclude that it is important to focus on shootings that result in a fatality, because they are more likely to be uniformly reported across communities and over time. During the time period between 1995 and 2019, the focus of our analysis, there were 176 school shootings that meet our criteria; they resulted in 302 fatalities.

The distribution of the number of fatalities per shooting is quite skewed. Eighty percent of the shootings resulted in one fatality, 11 percent resulted in 2 fatalities, and 5 percent resulted in 3 fatalities. A smaller percentage of school shootings generated a disproportionate share of the deaths, with the largest number of fatalities at Columbine High School in 1999 (15 fatalities), Marjory Stoneman Douglas High School in 2018 (17 fatalities), and Sandy Hook Elementary School in 2012 (28 fatalities). All of the these most extreme incidents were categorized by CHDS as "indiscriminate" shootings, indicating that they were not targeted at specific individuals.

Figure 1 shows patterns in these data over time. It documents that the number of shootings has not changed very much over time. In most years, the number of fatalities is close 
to the number of shootings, reflecting the fact that the majority of school shootings generate a single fatality. However, the number of fatalities spikes in years with high-victimization events.

The variation in school shootings raises the possibility that there may be heterogeneity in the impacts. It is plausible, for instance, that impacts increase with the number of fatalities or vary with the category of shooting. In addition, it is possible that schools and communities respond differently to some types of shootings and that this variation in responses can mediate the impact. In our analysis, we therefore allow for some heterogeneity by indiscriminate status and number of fatalities.

We also note that the CHDS data document the gender of shooters for 89 percent of shootings in its database and the gender of victims for 86 percent of shootings. Among shootings with fatalities that occurred on school days and during school hours since 1995, these data indicate that 90 percent of shooters - and 100 percent of indiscriminate shooters - were male. The data also indicate that 86 percent of the shootings had at least one male victim, whereas 33 percent had at least one female victim. These differences by gender are relevant for our subsequent discussion regarding differential effects of school shootings by gender.

We append several sources of data to the school shooting data to examine the impact of these events on educational outcomes, school finances, and subsequent mortality. In Table 1, we provide a summary of these additional data sources, including the outcome measures, the sample periods, and the number of shootings that we analyze along with a brief description of the empirical methods that we use. We discuss each of these data sources and our methods in greater detail below. 


\section{Impact on Test Scores}

\section{A. Data}

The first source of data we use to examine the impact of school shootings on test scores is the Stanford Education Data Archive (SEDA). As noted in the first row of Table 1, these data include English Language Arts and Math test scores for grades 3 through 8 for school years from 2008-09 to 2015-16. Mean test scores are provided at the school district level. Because each state can administer a different test, the researchers linked the state-specific test scores to National Assessment of Educational Progress (NAEP) test scores to convert the state scores to a common, normalized scale. Thus, the average SEDA-reported test score measure is zero and the unit of measure is interpreted as standard deviations in test scores relative to the national cohort.

Given the sample period, our analysis of the impact of school shootings on test scores is limited to shootings that occurred during the school years ending between 2009 and 2016. In addition, because these data only include test scores administered in grades 3 through 8 , we focus our analysis on 14 school shootings that affected elementary and middle schools during this time period. Each of these shootings resulted in a single fatality, except for the indiscriminate shooting at Sandy Hook Elementary School, which resulted in 28 deaths.

These data possess some limitations for our analysis. First, limiting our analysis to these 14 shootings reduces our statistical power. Second, data are reported as means for entire school districts. Even if test scores for students in a single school are affected by their exposure to a school shooting, the impact on the overall mean for the district may be small, especially in larger, urban school districts. As we show in Levine and McKnight (2020), shootings classified as personally-targeted or crime-related are more likely to occur in these areas. Thus, our ability 
to identify an impact on test scores, particularly for these other types of shootings, may be limited even if such an effect exists.

We complement our analysis of SEDA test score data with additional, publicly-reported information from the state of Connecticut, as described in the second row of Table $1 .{ }^{4}$ This part of the analysis focuses specifically on educational outcomes of students in Newtown, CT following the Sandy Hook Elementary School shooting. The advantage of this additional data source is that it allows us to examine test scores at the school level and to explore the pattern of effects across schools that are directly-affected and other schools in the district. The data include indicators of proficiency at the school and grade level ( $3^{\text {rd }}$ through $8^{\text {th }}$ grades $)$ between 2007-08 and 2017-18.

We focus on $3^{\text {rd }}$ and $4^{\text {th }}$ grade test results in these data. Since Sandy Hook enrolls students through $4^{\text {th }}$ grade, once students move beyond that level, they mix with students from other schools. This prevents us from consistently tracking differentially exposed students. For this analysis, we construct a balanced panel of data from 267 elementary schools in 87 districts between 2008 and 2018. The state did not report test score data in 2014 due to a transition to a new test format. Because proficiency rates are not directly comparable before and after the transition, our analysis focuses on each school's percentile within the distribution of proficiency rates across all the schools in the state for a given grade level, subject, and year. ${ }^{5}$

\footnotetext{
${ }^{4}$ Data beginning in 2014-15 is publicly available at http://data.ctdata.org/data_by_topic\#education. Data from earlier years was publicly available at the website, www.ctreports.com. We accessed these data in 2019, but that website was shut down in January of 2020.

${ }^{5}$ After the transition to the new test, we observe the share of students who "met or exceeded" standards, instead of the share who were "proficient." Note that the rate is suppressed from the data, and the school is therefore excluded from our panel, when the count of students in a particular category falls below six. In order to maintain a full panel of schools in the Newtown district, however, we impute missing values (using the assumption that the suppressed value is 5) in the few cases where data are missing. Our results are similar if we exclude these imputed observations.
} 


\section{B. Descriptive Analysis}

Before conducting a formal statistical analysis, we report the results of a descriptive analysis of the effects of the Sandy Hook school shooting using school-level data from Connecticut. These data include percentile scores based on a school's performance in math and English and language arts (ELA). We restrict the sample to scores from the $3^{\text {rd }}$ and $4^{\text {th }}$ grades, as described previously. To simplify the descriptive exercise, we average percentile scores across the two grades within the school and across subject areas (i.e. the average of four scores per school). For this analysis, we compare patterns in these averaged percentile scores between Sandy Hook Elementary, other Newtown elementary schools, and other elementary schools in the state. Because of the circumstances of the shooting, no test results are available for any school in the Newtown district in 2012-13 or, as we described earlier, for the entire state in 201314 due to a transition in the state standardized test.

Given these data issues, any impact of the shooting on test results would be observed between 2011-12 and 2014-15. Our available "post” data from 2014-15 and 2015-16 test results for $3^{\text {rd }}$ and $4^{\text {th }}$ graders includes students who were exposed to the shooting, observed two or three years afterwards.

The results of this analysis are presented in Figure 2. Newtown, CT is a high-income town with strong public schools. Its scores are typically much higher than state averages, which is verified by the very high proficiency rates prior to the shooting, in the $80^{\text {th }}$ to $90^{\text {th }}$ percentile range. At other elementary schools in the state, the average percentile is consistently around 50, by design.

At Sandy Hook, test results fell dramatically after the shooting. Two years later in 201415, our measure is still 20 percentile points lower than it was beforehand. Results rebounded 
somewhat over time as the affected cohorts aged out of the school. At other Newtown elementary schools, these data suggest that test scores fell as well, suggesting a broad impact within the district.

\section{Econometric Analysis}

The descriptive analysis highlights the impact of the Sandy Hook school shooting, but we conduct an econometric analysis to formalize our findings and examine the impact of the full set of relevant shootings. We use district-level data for the nation from SEDA, which enables us to incorporate test scores from additional grade levels, additional districts that were affected by other school shootings, as well as unaffected school districts across the country. In addition, we can separately analyze scores for boys and girls.

Our empirical strategy tests for differences in outcomes in geographic locations that were affected by school shootings, among cohorts of students who were exposed to school shootings, in the years after the school shootings occurred. It is therefore a triple-difference strategy that is characterized by the following regression equation:

$$
\text { TestScore }_{g d t}=\alpha+\beta \text { Exposed }_{g d t}+\gamma_{t}+\delta_{g}+\theta_{d}+\gamma_{t} \delta_{g}+\gamma_{t} \theta_{d}+\delta_{g} \theta_{d}+\varepsilon_{g d t}
$$

Where $g$ represents grades, $d$ represents school districts, and $t$ represents time. Our key

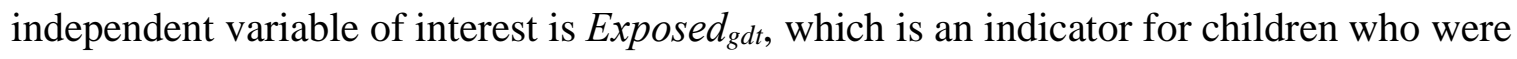
exposed to a school shooting. The impact of a school shooting is therefore identified by variation at the grade/district/year level.

Our regressions include a full set of second-order interactions between grade, district, and year. These interactions control flexibly for any trends in outcomes that may vary by age group or geographic area, and for any local differences in outcomes for different age groups. Regressions are weighted by enrollment in grade level $g$ in school district $d$ in year $t$. Standard 
errors are clustered at the district level. To reduce computational complexity, we collapse data for all districts where no school shooting occurred within a state into a single composite statelevel control group.

Table 2 presents the results of this analysis. The top panel shows results for all shootings, and we see that, collectively, school shootings do not have a statistically significant impact on standardized test scores overall or for boys or girls.

In the middle panel, we distinguish types of shootings. As indicated earlier, data limitations require us to focus on shootings that occurred in elementary and middle schools, limiting our sample to 14 of these events. Only one (Sandy Hook) led to more than one fatality. In this part of the analysis, we distinguish those with more than one death (Sandy Hook) from all the other shootings.

We find no statistically significant effect on test scores for those shootings with one death, but Sandy Hook led to a significant reduction in test scores in both subject areas. The impact for boys is larger than the impact for girls. The exact impact depends on the test but, on average, boys' scores fell by 0.1 of a standard deviation of and girls' scores fell by 0.06 . The effects on boys and girls are statistically significantly different from each other. The impacts are substantial, particularly for an analysis conducted at the level of district means. The larger impact on boys is consistent with other evidence suggesting that boys suffer greater educational consequences from other environmental disadvantages (See, for example, Bertrand and Pan, 2013; Autor et al., 2015; Chetty et al., 2016; and Kearney and Levine, 2016).

We note that the lack of a significant effect of the other shootings (those with one fatality) on test scores does not mean one does not exist. Even if there are substantial effects in the affected schools, when the test scores are averaged with the rest of the unaffected schools in 
the district, they may not be statistically apparent, especially relative to the typical random variability in test scores.

At Newtown, though, the shooting at Sandy Hook Elementary could have had an impact on learning not only for the students in the school, but also at other schools in the district where siblings, friends, and acquaintances attended school. We provided limited evidence of this earlier in our descriptive analysis and pursue it further in an econometric framework by examining test score data from the state of Connecticut. As described above, we focus on $3^{\text {rd }}$ and $4^{\text {th }}$ grade test scores only, when students are enrolled in elementary school.

More formally, we estimate a difference-in-differences model that is characterized by the following regression equation:

$$
\begin{gathered}
\text { TestScore }_{g s t}=\alpha+\beta_{1} \text { SandyHook }_{s} * \text { Post }_{t}+\beta_{2} \text { OtherNewtown }_{s}{ }^{*} \text { Post }_{t}+ \\
\gamma_{t}+\delta_{g}+\theta_{s}+\theta_{s}{ }^{*} \text { trend }_{t}+\varepsilon_{g s t}
\end{gathered}
$$

where test scores are measured for grade level $g$ in school $s$ and year $t$. Our identification, though, comes only at the level of schools over time ( $s$ and $t$ ). Our analysis includes school fixed effects, year fixed effects, grade-level fixed effects, and school-specific linear time trends. Regressions are weighted by the enrollment in grade level $g$ in school $s$ and year $t$. Standard errors are clustered at the school district level.

We also note that the outcome in this analysis is the school's percentile in the state proficiency rate distribution for the specific test and grade. As we described earlier, the specific test administered changed in 2013-14, so direct comparisons of proficiency rates before and after the transition would be inappropriate. Instead, we convert these data to percentiles, which should be comparable over time. We also note that these data are not available by gender, so we cannot compare the estimated effects between boys and girls. 
Our results, displayed in Table 3, show that there were effects on test results throughout the school district. In the years following the shooting at Sandy Hook, average $3^{\text {rd }}$ and $4^{\text {th }}$ grade test scores fell by 26 and 6 percentile points in math and ELA, respectively. Students at other Newtown elementary schools experienced diminished performances as well. Their average test scores fell by 35 and 18 percentile points in math and ELA, respectively. The small size of the Newtown district (only 4 elementary schools) may contribute to the considerable impact at other Newtown schools. The results are consistent with the earlier results using SEDA data, reported in Table 2, indicating larger effects on math scores than ELA.

\section{Interpreting the Results: The Impact of Mobility}

One limitation of this analysis is the issue of mobility. Students living near the site of a school shooting may move away or enroll in a private school in subsequent years. Prior research suggests that these incidents can affect enrollment patterns (e.g. Abouk and Adams, 2013, Beland and Kim, 2016). If that mobility were random in terms of the students/families who chose to move, it would not bias our results. It is plausible, though, that students who move are not randomly selected. If higher-scoring students are more likely to move away (or enroll in a local private school), for instance, this could introduce bias, overstating the impact of a shooting on test scores.

We use the NCES Common Core of Data (Common Core) and publicly-reported data from Newtown Public Schools on enrollment in elementary schools to see whether such mobility occurs. If enrollments drop in the immediate aftermath of a shooting, it would indicate that some students moved away from the school where the shooting occurred and raises the possibility of bias. 
The Common Core include information on enrollment in each school district. Using these data, we estimate difference-in-difference models (district and year) of the impact of a school shooting on enrollments. The results indicate a negative, but insignificant effect of enrollments in response to all types of school shootings, but a 7.2 percent decline in enrollments in response to an indiscriminate shooting with greater than 1 fatality (significant at the 10 percent level). This impact is at the district level, which likely understates the impact at the specific school that has experienced a shooting.

We also track enrollments for the 2010 through 2014 kindergarten entry cohorts in Sandy Hook Elementary using data presented in Prowda (2019). These data include the number of students born in each cohort residing in the Sandy Hook school attendance zone. In these data, we see similar evidence of mobility in the year after the shooting. The magnitude of the decline is comparable to the 7 percent decline we estimated using Common Core data. The evidence is strongly suggestive that some families left the school because of the shooting.

Although outmigration potentially biases our results, the bias is unlikely to be large. Suppose, for instance, that a class at Sandy Hook had a mean percentile score of 90 before the shooting, consistent with the data shown in Figure 2. Of that class, suppose that 10 percent moved away as a result. If those students were all in the $99^{\text {th }}$ percentile, this mobility would reduce the average percentile score from 90 to 89, in the absence of any causal effect of the shooting on test scores. We observe an impact that is far greater than that. Although mobility is an issue that should be kept in mind, it is unlikely to be substantively driving our findings.

\section{E. Spillovers to Other Communities}

One potential limitation of this analysis is that the impact of a shooting may be understated because the "control group” may be indirectly affected. Events such as the Sandy 
Hook school shooting, for example, were so highly publicized and broadly traumatic that children elsewhere could have been affected by it. We have already shown that it had an impact on test results at other schools within the district. To the extent that "unaffected" students outside of the school district where the shooting occurs are adversely affected, our analysis will understate effects on those who were directly exposed.

Indeed, past research shows that traumatic events can have widespread impacts. For instance, the psychological effects of the September $11^{\text {th }}$ terrorist attacks were not limited to those who directly experienced them. Silver et al. (2002) report that 17 percent of the U.S. population outside of New York City reported symptoms of post-traumatic stress two months after the attacks, with 6 percent continuing to report such symptoms after 6 months. In the aftermath of a 2008 school shooting in Finland, matriculation test scores fell throughout the country, with the effects concentrated among males (Poutvaara and Ropponen 2018).

To assess the degree of spillovers in our setting, we extend our analysis of the Sandy Hook shooting to examine its impact on test results of students from other nearby school districts in the state with comparable socioeconomic status. We estimate that the shooting had no significant impact on test results at these other schools. Although we see no evidence suggesting broader impacts outside of the district, we note that if such an impact occurred, it would cause us to understate the impact inside the district.

\section{Impact on Chronic Absenteeism}

In this section, we explore the impact of the shooting on chronic absenteeism, which is defined as being absent for 10 percent or more of the school days in an academic year. If students missed substantially more school as a result of exposure to the shooting, it could contribute to the drop-off in their average performance. 


\section{A. Data and Descriptive Analysis}

We are aware of no national data on chronic absenteeism that we could use to estimate the impact of a school shooting on this outcome. Instead, we rely exclusively on publiclyavailable data from the state of Connecticut, available at edsight.ct.gov. As noted in the third row of Table 1, these data are available at the school, but not grade, level. We focus our attention on Sandy Hook Elementary and other Newtown elementary schools, comparing their patterns of chronic absenteeism to other elementary schools in the state. ${ }^{6}$ Restricting these data to elementary schools makes this analysis consistent with our examination of test scores. We examine a balanced panel of these schools, spanning the school years, 2011-12 through 201819. ${ }^{7}$

We initially use these data to conduct a descriptive analysis of the impact of the Sandy Hook school shooting on chronic absenteeism. We report chronic absenteeism in the years following the shooting relative to the level that existed in 2011-12, before the event occurred. Note that the exact date of the shooting was December 14, 2012, so the data point for 2012-13 represents half of a year in its aftermath.

The results of a descriptive analysis of these data are reported in Figure 3. Each data point in the figure represents the percentage point change in chronic absenteeism rates between each year and the baseline. The rate of chronic absenteeism at Sandy Hook Elementary in 201112 was 2.2 percent. In 2013-14, the first full year following the shooting, this rate had nearly tripled, increasing over 4 percentage points. This effect appears to dissipate in subsequent years,

\footnotetext{
${ }^{6}$ These data do not directly indicate whether the school is an elementary school. We merge Connecticut test score data to the enrollment data and focus on the same set of schools used in the test score analysis.

${ }^{7}$ Note that the chronic absenteeism percentages are bottom-coded; if it falls below a certain number of students, a school's absence rate is coded as missing in the data. In cases of missing data, we use the lowest percentage of chronic absences that is observed in other years to maintain a balanced panel of schools. Our analysis of these data is not affected when we omit these observations.
} 
as one might expect as cohorts age out. We also observe a smaller increase in chronic

absenteeism at other Newtown elementary schools, which dissipated more quickly.

\section{B. Econometric Analysis}

We estimate a difference-in-differences specification, comparable to the one represented in Equation 2, replacing test scores with chronic absenteeism rates as the dependent variable. Because absenteeism is not reported for each grade level, we exclude the grade fixed effects. More formally, the model we estimate takes the form:

$$
\begin{gathered}
\text { ChronicAbsenteeism }_{s t}=\alpha+\beta_{1} \text { SandyHook }_{s} * \text { Post }_{t}+\beta_{2} \text { OtherNewtown }_{s} * \text { Post }_{t}+ \\
\gamma_{t}+\theta_{s}+\theta_{s} * \text { trend }_{t}+\varepsilon_{s t}
\end{gathered}
$$

The results of this analysis are reported in the final column of Table 3. They suggest that, in the aftermath of the shooting, there was a 3.4 percentage point increase in chronic absenteeism at Sandy Hook Elementary School, with a 1.2 percentage point increase at other schools in the district. These declines are large relative to the 2.2 and 3.0 percent baseline rates of chronic absenteeism from 2011-12 at Sandy Hook and other Newtown elementary schools, respectively.

While we cannot observe the distribution of absence rates in each school, it is reasonable to suppose that absences increased throughout the distribution, not only in the tail that is considered “chronic.” We note that Cabral, et al. (2020) find a 0.4 percentage point increase in absences as well as an increase in chronic absenteeism, following school shootings that have zero or one fatality in their analysis of data from Texas. ${ }^{8}$ The increase in school absences offers a plausible mechanism for some of the decline in test scores as Sandy Hook Elementary School and in the other elementary schools in the Newtown district.

\footnotetext{
${ }^{8}$ Our analysis of high fatality shootings finds that chronic absenteeism rose by 155 percent. Cabral, et al. (2021) finds a 28 percent increase in chronic absenteeism in response to shootings that lead to either zero or one fatality.
} 


\section{Impact on School Expenditures}

One would also anticipate that schools that have experienced a school shooting work hard to improve the school environment in an effort to help reduce the impact on affected students. This section examines the financial implications on the schools that have had the misfortune of such an event.

\section{A. Data and Descriptive Analysis}

To examine the impact of school shootings on school spending patterns, we use districtlevel data from the Common Core School District Finance Survey data for the years 1995 to 2016. These data are described in rows 4 and 5 of Table 1 . We focus on data for school districts for which we observe the full 22 years of data, generating a panel data set. The categories of spending that we examine are total expenditures, non-capital expenditures (including all expenses except for capital outlays for construction, land, and equipment), expenditures for instruction, support services, and other expenditures. Instructional spending includes payments for salaries for teachers, teacher aides and assistants, benefits, supplies and materials for instruction. Support services includes a wide range of expenditures, including the costs of administration and record-keeping, student transportation, libraries, building services such as heating and security, and nursing, psychological, and speech services for students. Examples of other expenses include adult education, payments to other school systems, and interest on debt.

The long availability of these data enables us to examine the impact of many more of the incidents that our shootings database contains. We focus on those that occurred between 1998 and 2013, allowing us to observe each school district for at least three years before and after each school shooting. Because the data are at the district level, we can examine shootings at all levels of public schools, including elementary schools, middle schools/junior high schools, and high 
schools. For this analysis, we examine the impact of 105 of the 176 school shootings in our data that occurred within the 1998-2013 period (allowing for a three-year window before and after the shooting). We also separately examine the impact of the Sandy Hook school shooting on district spending relative to other districts in the state of Connecticut.

We conduct a descriptive analysis of district-level spending on support services, focusing on the six indiscriminate shootings in our sample period that resulted in more than one fatality. School spending is a district-wide decision, making this the appropriate level of analysis for such an exercise. The districts that experienced such a shooting are those that include the following schools: Sandy Hook Elementary (2012), Heath High School (1998), Westside Middle School (1998), Columbine High School (1999), Red Lake High School (2005), and Chardon High School (2012). We detrend all spending data (1995 is the baseline) and then compare levels of district-level spending in the few years before and after each shooting occurred.

The results of this analysis are reported in Figure 4. The data show that spending on support services increased from around $\$ 2,200$ per student per year to around $\$ 2,800$ per student per year in the year following a shooting, representing a 27 percent increase. It remained elevated for at least three years afterward.

\section{B. Econometric Analysis}

We extend this analysis by estimating econometric models of school spending by category and by type of shooting. Our specification is analogous to that indicated in Equations 2 and 3, but focusing on an interaction between the type of school shooting and an indicator for post, while controlling for year and district fixed effects and district-specific time trends.

$$
\ln \left(\text { Expenditure }_{\mathrm{st}}\right)=\alpha+\beta_{1} \text { ShootingType }_{d}{ }^{*} \text { Post }_{t}+\gamma_{t}+\mathrm{d}_{s}+\theta_{d} * \text { trend }_{t}+\varepsilon_{\text {ast }}
$$


Based on preliminary analyses, we specifically focus on the impact of indiscriminate shootings, distinguished by the number of fatalities that result, relative to other types. Similar to our analysis of test scores, we collapse the data for school districts within a state that experienced no shooting into a single, composite state-level control group for computational simplicity.

Table 4 presents our regression results, with a different measure of spending reported in each column. We measure the expenditures as the natural log of expenditures per student, so coefficients can be interpreted as percentage changes in per-pupil spending. The top panel aggregates all types of shootings. We find no statistically significant impact on overall spending, but we do find a small, significant, positive effect on spending on support services.

The middle panel distinguishes types of shootings. All types increase support services spending by at least a small amount, but indiscriminate shootings that result in more than one death are clearly different. In those districts, spending on support services jumps by one-third. Other forms of spending increase as well, leading to a 10 percent increase in overall spending. The capital expenditure component of total expenditures generates very large year-to-year variation in district spending when new building projects are undertaken. Thus, in the second column, we exclude capital expenditures and find that per-pupil, non-capital expenditures increase by 17 percent in the aftermath of indiscriminate school shootings with more than one fatality. ${ }^{9}$ The fourth column shows a small, statistically significant increase in instructional spending, while the final column shows a statistically significant 24 percent increase in "other" spending. This category contains a range of expenditures that could be impacted by a school shooting. For instance, it includes interest payments on debt - which would increase with debt-

\footnotetext{
${ }^{9}$ In an analysis of school district revenues, we see an offsetting, statistically significant increase in revenues in districts that experience an indiscriminate shooting with more than one fatality. This increase is driven by a statistically significant 15 percent increase in local tax revenue. Thus, the increased costs of operating schools in the aftermath of such a shooting appear to be borne primarily by the local community.
} 
financed school construction projects - and payments to private school systems, charter schools, and private schools - which could increase with changing enrollment patterns.

The bottom panel of Table 4 repeats the analysis focusing specifically on the state of Connecticut and the Sandy Hook school shooting. We estimate a model analogous to Equation 4, but replace the shooting type indicator with a Newtown, CT indicator (since it is a district-level analysis). The results indicate that the impact of Sandy Hook on school finances in Newtown was similar to the broader effect of indiscriminate shootings where more than one person was killed. The impact on spending on support services was smaller, but it still increased by 13 percent following the shooting.

The evidence reported here indicates that school districts respond differentially to an event as extreme as an indiscriminate school shooting with multiple fatalities. Using national data (which drive the analysis in the middle panel of Table 4), the median school district in 2016 had \$11 million in annual expenditures (or \$10 million if capital expenditures are excluded). A 10 percent increase in spending would cost such a district $\$ 1.1$ million per year. Of course, the human tragedy in such an event is paramount, but it is noteworthy that school shootings generate meaningful financial consequences for affected school districts. It is also noteworthy that this additional spending appears insufficient to prevent a reduction in educational performance.

\section{Impact on Subsequent Mortality}

We next examine subsequent mortality for survivors of school shootings using countylevel Vital Statistics data between 1995 and 2017. Mortality is unquestionably an extreme health outcome. Even if there are long-term health consequences of exposure to a school shooting, it is plausible that there would be no mortality effect or that the mortality effect would be too small to separate from the random variation in mortality across cohorts and years. If there are mortality 
effects, on the other hand, there are likely effects on other health outcomes that are less easily measured.

\section{A. Data}

As described in the sixth row of Table 1, we use county-level Vital Statistics mortality data between 1995 and 2017 for our analysis of the impact of shootings on subsequent mortality for cohorts who were exposed to school shootings. These data represent every death that occurred in the United States along with the information contained on death certificates, including month of death, detailed cause of death, and demographic details of the deceased (age, sex, and race/ethnicity). The deceased's state and county of residence is restricted, but it can be obtained by researchers under an agreement with the National Center for Health Statistics. Because deaths are reported based on current residence, not residence during high school, mobility is a potential problem in this analysis as well. A similar simulation as we described regarding test scores is appropriate here, however, suggesting it is extremely unlikely to substantively bias our results.

For our analysis, we measure deaths per 1,000 population, using data from the Surveillance, Epidemiology, and End Results (SEER) program to measure the population. We separately examine external and non-external causes of deaths. ${ }^{10}$ Among external deaths, we focus specifically on those caused by suicides, homicides, and other accidents (which include accidental poisonings/drug overdoses).

We examine subsequent mortality through age 29 for the cohorts who were exposed to school shootings. For this analysis, we focus on shootings that affected children of high school age (14 to 18) between 1995 and 2012, allowing us to observe mortality outcomes at least for

\footnotetext{
10 These categories are not inclusive of all causes of death.
} 
several years following the shooting event. ${ }^{11}$ During our sample period, there were 103 that affected high school-age students; seven of these were indiscriminate shootings. Eighty-nine of the shootings resulted in a single fatality. Eleven shootings resulted in two or three fatalities. The shooting at Columbine High School in 1999 had the greatest number of fatalities, with 15 (including the two shooters).

One weakness of these data is that they are available at the county level, not narrower geographic areas that would better reflect school district boundaries. Many students in a county where a school shooting took place did not attend the affected school. The focus on a somewhat broader geographic area makes it more difficult to identify an effect, a limitation that needs to be taken into consideration in interpreting the results of this analysis.

\section{B. Descriptive Analysis}

Before conducting a formal statistical analysis, we conduct a quasi-experimental analysis of the Columbine High School shooting, which took place in Jefferson County, Colorado, on April 20, 1999 (during the 1998-99 school year). Using the Vital Statistics Mortality data, we construct age-specific death rates for those between the ages of 14 and 29 for residents of Jefferson County and all other counties in the state separately for each year between 1995 and 2017. We identify the cohort of "exposed" students who were potentially present at the school shooting by identifying death rates among individuals who were residents of Jefferson County and between the ages of 14 and 18 in 1999 . We track death rates for that cohort as they age (15 to 19 in 2000, 16 to 20 in 2001, ...), assuming no mobility.

We also construct similar death rates for the same age-ranges from other years ("nonexposed” Jefferson County residents, aged 14 to 18 in years other than 1999, etc.) to set a

\footnotetext{
${ }^{11}$ This may include shootings that occurred at a middle school, which would have 14-year old students enrolled.
} 
baseline death rate by age category in that county. Differencing those sets of statistics from Jefferson County provides one estimate of cohort differences between students exposed to Columbine and other cohorts within Jefferson County.

To abstract from potential idiosyncrasies across cohorts, we conduct the same exercise using age/year specific mortality rates for the rest of the state outside of Jefferson County. Differencing these two sets of differences provides a baseline test of the impact of exposure to the Columbine shooting on subsequent mortality. To summarize, we calculate the following statistic:

$$
\begin{gathered}
\left(\mathrm{MR}_{\text {Exposed Cohort/Jefferson County }}-\mathrm{MR}_{\text {Unexposed Cohort/Jefferson County }}\right)- \\
\left(\mathrm{MR}_{\text {Exposed Cohort/Other County }}-\mathrm{MR}_{\text {Unexposed Cohort/Other County }}\right)
\end{gathered}
$$

at ages 14-18, 15-19, 16-20, ..., using the 1995 through 2017 mortality data. Tracking this statistic as individuals age provides a way to gauge the impact of the Columbine shooting on the mortality patterns of shooting survivors.

Figure 5 reports the results of this analysis. The first bar in this figure, which is visually separated from the others, shows the impact on mortality in the year of the shooting on the exposed cohort. It captures the direct impact of the shooting itself. It is not surprising that the mortality rate for the 14-18-year-olds in Jefferson county was differentially higher in this year.

The remainder of the figure explores the impact on mortality at subsequent ages. The figure shows that, while mortality rates dipped downward in the initial years following the shooting (perhaps reflecting increased support services), mortality rates eventually increased, and the increase persisted through the exposed cohort's twenties. Of course, this figure provides no standard errors and does not tell us anything about the causes of death. But it does provide 
suggestive evidence that the shooting at Columbine High School may have had long-term impacts on mortality for the exposed cohort.

\section{Econometric Approach}

As in our past analyses, we conduct a more formal econometric analysis to examine the impact of exposure to a school shooting on subsequent mortality. We continue with our focused analysis on the impact of the Columbine shooting and then broaden the discussion below to the larger pool of all shootings we consider. The approach we use here is a triple difference estimation strategy similar to that described earlier in Equation 1 regarding test scores. One main difference here is that the data are organized by age $(a)$, year $(t)$, and county of residence $(c)$. We track cohorts over time, distinguishing between the contemporaneous effect in 1999 from the subsequent effects in the years after that. Equation 5 provides a formal specification of this model.

$$
\begin{gathered}
\text { MortalityRate }_{a c t}=\alpha+\beta_{1} \text { ExposedCurrent }_{a c t}+\beta_{2} \text { ExposedPost }_{a c t} \\
+\gamma_{t}+\delta_{a}+\theta_{c}+\gamma_{t} \delta_{a}+\gamma_{t} \theta_{c}+\delta_{a} \theta_{c}+\varepsilon_{a c t}
\end{gathered}
$$

The mortality rate represents deaths per 1,000 population. In this context, Exposed reflects the fact that a student was in an age group and residing in a county (in this case, Jefferson County, $\mathrm{CO}$ ) at the time that a school shooting took place (again, assuming no mobility). The ExposedCurrent coefficient $\left(\beta_{1}\right)$ is capturing the same concept as the first bar in Figure 5 and the ExposedPost coefficient $\left(\beta_{2}\right)$ is capturing the same concept as the average of the remaining bars in that figure. We estimate this model separately for boys and girls based on our earlier analysis indicating that the impact of a shooting may differ by gender.

The results of this analysis are reported in Table 5, with results for boys in the top panel and for girls in the bottom panel. For boys, we see increases in contemporaneous deaths driven 
by external deaths and, specifically, homicides and suicides, as one would expect based on the nature of the shooting. ${ }^{12}$

Note that since the coefficients are measured as mortality rates per 1,000 population, we can multiply them by the cohort size in 1,000s (exposed cohorts are those between ages 14 and 18, distinguished by sex - values are shown in the notes to Table 5) to calculate an estimated number of additional deaths. The implied, estimated numbers of excess deaths are generally consistent with the actual impact of the shooting, providing some support that our econometric approach is appropriately describing the effects.

In terms of subsequent deaths, we find that both suicides and accidental deaths increased for boys, leading to an overall increase in external deaths. We augment our earlier approach to calculate the estimated number of deaths by noting that Columbine survivors remained in our data through age 29, or an average of 13 additional years for those between 14 and 18 in 1999 . Our point estimates would imply that 9.8 additional suicides $(0.038 \times 19.9 \times 13)$ and 8.8 additional accidental deaths $(.034 \times 19.9 \times 13)$ occurred among survivors through age 29 . We see no statistically significant effects on suicides or accidental deaths for girls. Some spurious changes in mortality patterns are also evident in these data, but nothing that would suggest a broader movement towards higher mortality among this cohort.

We also estimate the impact of all 103 shootings that affected high school-age (14 to 18) students identified in our sample period that led to a fatality in our analysis, distinguished by category. The results of this analysis are reported in Tables 6A (boys) and 6B (girls). Overall, our methods largely are able to identify the impact of the different types of shootings on contemporaneously measured homicides and suicides, particularly for boys.

\footnotetext{
${ }^{12}$ At this incident, there were 15 deaths, including 13 homicides and 2 suicides. Ten of the student fatalities were male.
} 
Consistent with what we observed in Columbine, this evidence suggests that there is some excess subsequent mortality among boys following an indiscriminate shooting. Following an indiscriminate shooting with one fatality, these results indicate that accidental deaths rise. Suicides increase following a larger fatality, indiscriminate shooting (identified from five such events, including Columbine). For girls, the pattern appears to be different and does not tell a consistent story.

Taken as a whole, these results strongly suggest that high fatality, indiscriminate school shootings affect subsequent mortality patterns of boys. An analysis of less aggregated data would allow an identification strategy that is better able to pinpoint this impact. We view this as an important topic for future research.

\section{Discussion}

The trauma associated with exposure to a school shooting is hard to comprehend. It would be difficult to discount its potential to have long-lasting impacts on the lives of those who survive one. Identifying those effects, however, is a challenging task. Even though these shootings are all too common and affect too many people, the proportion of children affected is relatively small and the ways in which the effects may manifest themselves are not easily measured in publicly available, aggregated data.

Nonetheless, we find evidence of impacts on exposed children in the years following a shooting. Our strongest evidence comes in the form of lower test scores among students affected by the Sandy Hook school shooting and an increased risk of suicide or accidental deaths among students affected by the Columbine High School shooting. In both cases, boys were more susceptible to longer-lasting impacts. It is perhaps not surprising that our evidence is strongest in the most egregious examples of school shootings. The fact that boys are most affected may be 
partly attributable to the fact that boys are more likely to be victimized and that boys are often more responsive to negative shocks in their social settings.

We do not believe it would be appropriate to interpret the remainder of our results as indicating that students are not affected by other shooting incidents. Statistical inference does not allow us to draw that conclusion. In a setting with more statistical power to examine lowervictimization incidents, Cabral, et al (2020) find statistically significant, adverse impacts on educational and labor market outcomes. Similarly, Rossin-Slater, et al. (2019) conclude that the sales of anti-depressant drugs increases in the aftermath of school shootings.

In the end, we believe the combined weight of the evidence from our analyses, and the findings of other studies that complement our own, is consistent with a negative impact associated with exposure to any school shooting, with especially strong consequences from indiscriminate, high-victimization incidents. We conclude that the consequences of a school shooting go beyond the victims who are killed at the event itself. This is a topic that deserves more attention. 


\section{References}

Abouk, Rahi and Scott Adams (2013), “School Shootings and Private School Enrollment," Economics Letters 118(2): 297-299.

Ang, Desmond (forthcoming), “The Effects of Police Violence on Inner-City Students.” Quarterly Journal of Economics.

Autor, David, David Figlio, Krzysztof Karbownik, Jeffrey Roth, and Melanie Wasserman (2015). "Family Disadvantage and the Gender Gap in Behavioral and Educational Outcomes," IPR Northwestern working paper 15-16, October.

Bharadwaj, Prashant, Manudeep Bhuller, Katrine V. Løken, and Mirjam Wentzel (2020). "Surviving a Mass Shooting." Unpublished manuscript.

Beland, Louis-Philippe and Dongwoo Kim (2016). “The Effect of High School Shootings on Schools and Student Performance,” Educational Evaluation and Policy Analysis 38(1): 113-126.

Bertrand, Marianne and Jessica Pan, "The Trouble with Boys: Social Influences and the Gender Gap in Disruptive Behavior,” American Economic Journal: Applied Economics, January 2013, 5(1), 32-64.

Brener, Nancy D., Thomas R. Simon, Mark Anderson, Lisa C. Barrios, and Meg L. Small (2002). "Effect of the Incident at Columbine on Students' Violence- and Suicide-Related Behaviors." American Journal of Preventive Medicine, 22(3):146-150.

Cabral, Marika Bokyung Kim, Maya Rossin-Slater, Molly Schnell, and Hannes Schwandt (2020). “"Trauma at School: The Impacts of Shootings on Students' Human Capital and Economic Outcomes.” National Bureau of Economic Research working paper 28311.

Chetty, Raj, Nathaniel Hendren, Frina Lin, Jeremy Majerovitz, Benjamin Scuderi (2016). “Childhood Environment and Gender Gaps in Adulthood.” NBER Working Paper 21936.

Connecticut State Department of Education (various years). "School Profile and Performance Report." Hartford, CT: Connecticut State Department of Education.

Dursun, Bahadir (2019). “The Intergenerational Effects of Mass Shootings,” unpublished manuscript.

Helliwell, John F. (2004). "Well-Being and Social Capital: Does Suicide Pose a Puzzle?" Social Indicators Research 81(3): 455-496

Kearney, Melissa S. and Phillip B. Levine (2016). "Income Inequality and the Decision to Drop Out of High School.” Brookings Papers on Economic Activity. pp. 333-380. 
Lowe, Sarah R. and Sandro Galea (2017). "The Mental Health Consequences of Mass Shootings,” Trauma, Violence and Abuse 18(1): pp. 62-82.

North, Carol S., Sara Jo Nixon, Sheryll Shariat, Sue Mallonee, J. Curtis McMillen, Edard L. Spitznagel, and Elizabeth M. Smith (2001). "Psychiatric Disorders among Survivors of the Oklahoma City Bombing,” Journal of the American Medical Association 282(8) pp. 755-762.

North, Carol S., Elizabeth M. Smith, and Edward L. Spitznagel (1994). "Posttraumatic Stress Disorder in Survivors of a Mass Shooting,” The American Journal of Psychiatry 151(1): pp. 8288.

Poutvaara, Panu and Olli Ropponen (2018), "Shocking News and Cognitive Performance," European Journal of Political Economy 51: pp. 93-106.

Prowda, Peter M. (2019). Newtown Public Schools Enrollment Projected To 2029 (available at: https://newtown.campuscontact.com/ theme/files/District\%20Information/20192020\%20Enrollment/Prowda\%20Enrollment\%20Report\%209-24-19.pdf, accessed 12/8/2020).

Reardon, Sean F., Ho, Andrew D., Shear, Benjamin R., Fahle, Erin M., Kalogrides, Demetra, Jang, H., Chavez, Belen, Buontempo, J., and R. DiSalvo (2018). Stanford Education Data Archive (version 3.0). Retrieved from http://purl.stanford.edu/db586ns4974.

Riedman, David and Desmond O’Neill (2018). K-12 School Shooting Database: Research Methodology. Naval Postgraduate School, Center for Homeland Defense and Security, Homeland Security Advanced Thinking Program (HSx). https://www.chds.us/ssdb/methods/

Rossin-Slater, Maya, Molly Schnell, Hannes Schwandt, Sam Trejo, and Lindsey Uniat (2019). "Exposure to School Shootings Raises Youth Antidepressant Use.” Unpublished manuscript, Stanford University.

Sacerdote, Bruce (2012), "When the Saints Go Marching Out: Long-Term Outcomes for Student Evacuees from Hurricanes Katrina and Rita," American Economic Journal: Applied Economics 4(1): 109-135.

Sharkey, Patrick (2010), “The Acute Effect of Local Homicides on Children's Cognitive Performance,” Proceedings of the National Academy of Sciences 107(26): 11733-11738.

Silver, Rachel Cohen, E. Alison Holman, Daniel N. McIntosh, Michael Poulin, and Virginia GilRivas (2002). "Nationwide Longitudinal Study of Psychological Responses to September 11," Journal of the American Medical Association 288(10): pp. 1235-1244.

Smith, Nathan Daniel Lucia, and Ichiro Kawachi (2014). "State-Level Social Capital and Suicide Mortality in the 50 U.S. States.” Social Science and Medicine. 120 (November): 269-277.

Wilson, Laura C. (2017). "Mental Health Outcomes Following Direct Exposure”, in The Wiley Handbook of the Psychology of Mass Shootings, edited by Laura C Wilson. Wiley Blackwell. 
Figure 1: Number of School Shootings that Resulted in a Fatality and Total Fatalities

50

45

40

35

30

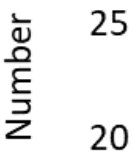

19951997

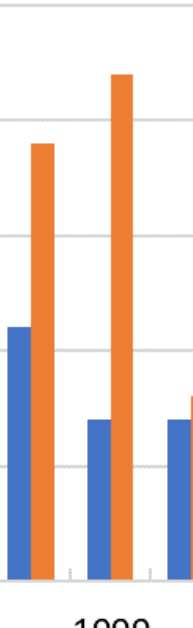

2001

2003

2005

n shootings

fatalities

source: Authors' calculations as described in Levine and McKnight (2020). 


\section{Figure 2: Average Combined Math and ELA Proficiency in 3rd and 4th Grades in Connecticut}

100

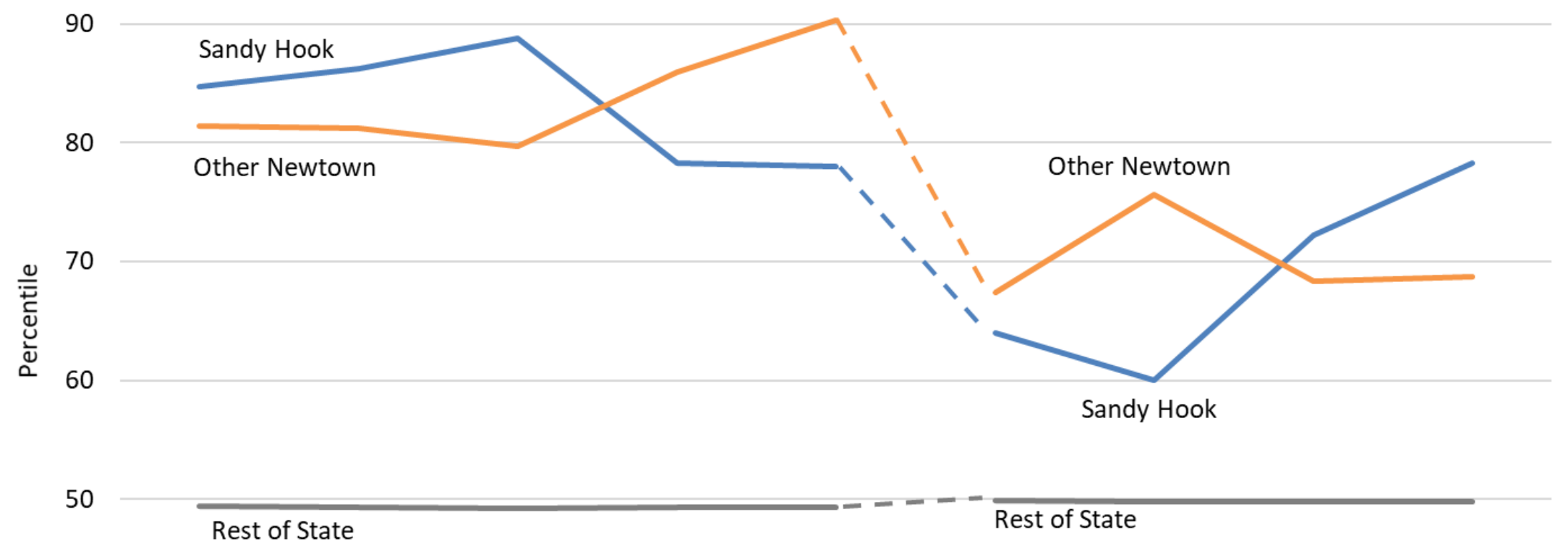

40

30

Source: Authors' calculations based on data from the State of Connecticut. Notes: "Proficiency" for 2014-15 and forward is defined as the percentage of students who meet or exceed expectations in each subject. 
Figure 3: Difference in Rate of Chronic Absenteeism Relative to 2011-12

$5 \%$

Hure 3: Differencein Rate of Chronic Absenteeism Relativeto $2011-12$

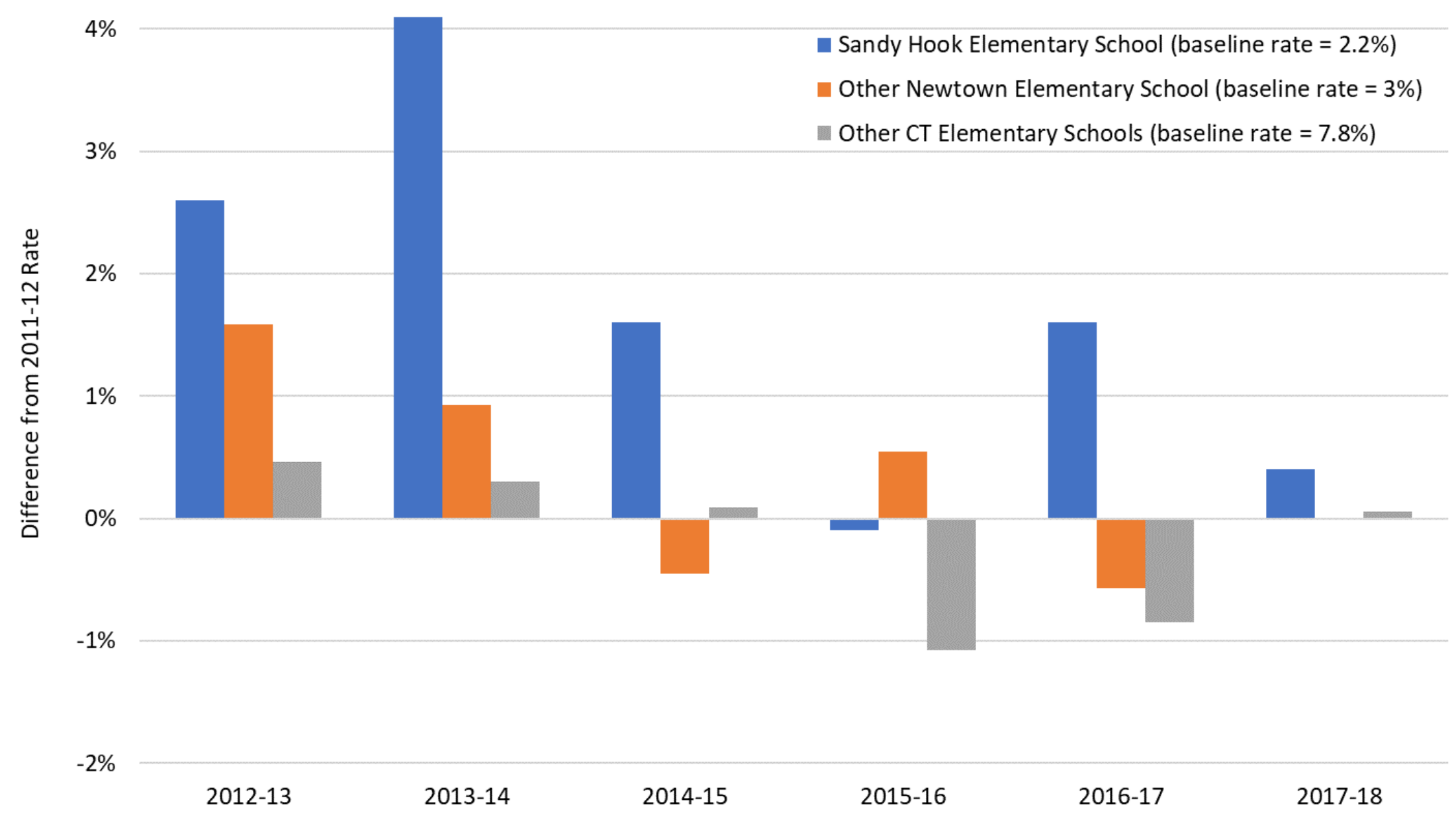

Source: Authors' calculations based on Common Core Data. 


\section{Figure 4: Expenditures Per Student on Support Services Before and After}

an Indiscriminate School Shooting with More Than One Fatality

$\$ 3,500$

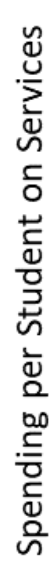

$\$ 3,000$

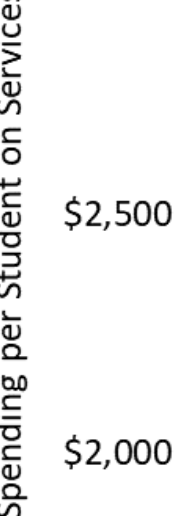

$\$ 1,500$

$-3$

$-2$

$-1$

0

1

2

Years Before/After Shooting

source: Authors' calculations based on analysis from the Common Core of Data from 1995 to 2016.

notes: spending is detrended with a baseline level set relative to (1995). There were six indiscriminate shootings with more than one

fatality in our sample window. 
Figue 5: Quasi-Experimental Estimates of the Impact of the Columbine School Shooting on Age-Specific Death Rates

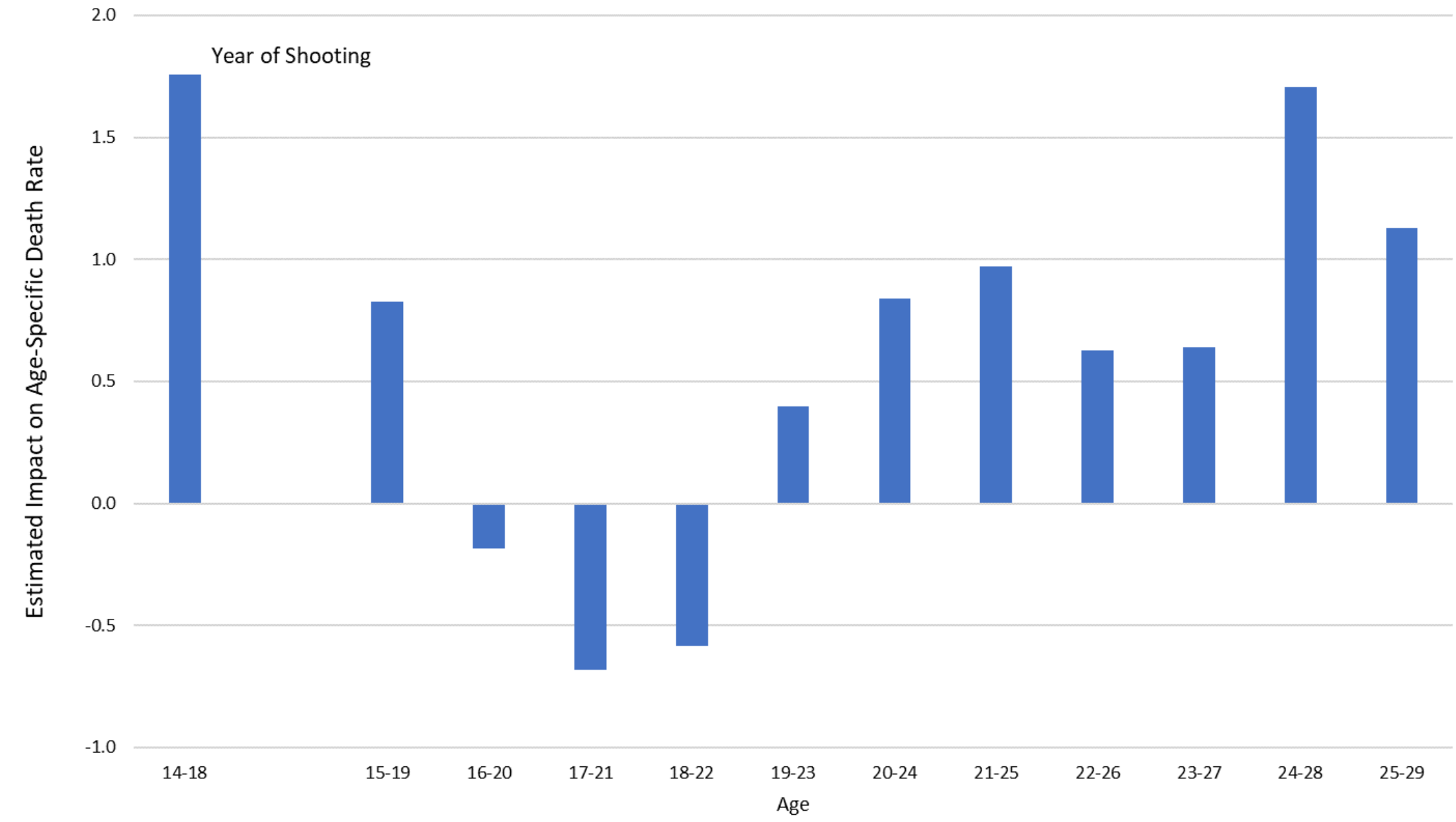

source: Authors' analysis of 1995 through 2017 Vital Statistics Mortality microdata. The estimated impact is calculated as the difference in death rates among Jefferson County residents in Columbine exposed cohorts versus other cohorts and the analogous difference among residents of other counties in Colorado. 
Table 1: Summary of Data, Outcomes, and Methods

\begin{tabular}{|c|c|c|c|c|c|}
\hline Outcome & Source & Data & Outcome Measure & Shootings & Method \\
\hline Test Scores 1 & $\begin{array}{l}\text { Stanford Education } \\
\text { Data Archive } \\
\text { (SEDA) }\end{array}$ & $\begin{array}{c}\text { Grades 3-8, } \\
\text { national, district-level, } \\
\text { 2009-2016, by gender }\end{array}$ & $\begin{array}{l}\text { z-scores from math } \\
\text { and ELA tests }\end{array}$ & $\begin{array}{l}\text { 14 Elementary/ } \\
\text { Middle School } \\
\text { shootings }\end{array}$ & $\begin{array}{l}\text { Triple Difference } \\
\text { (grade, district, } \\
\text { year) }\end{array}$ \\
\hline Test Scores 2 & $\begin{array}{l}\text { CT publicly } \\
\text { reported data }\end{array}$ & $\begin{array}{c}\text { Grades } 3 \text { and 4, } \\
\text { CT only, School-level, } \\
\text { 2008-2018 }\end{array}$ & $\begin{array}{l}\text { Percentiles of } \\
\text { proficiency on math } \\
\text { and ELA tests }\end{array}$ & $\begin{array}{c}\text { Sandy Hook } \\
(2012 / 13)\end{array}$ & $\begin{array}{c}\text { Diff-in-Diff } \\
\text { (school, year) with } \\
\text { school-specific } \\
\text { trends }\end{array}$ \\
\hline $\begin{array}{l}\text { Chronic } \\
\text { Absenteeism }\end{array}$ & $\begin{array}{l}\text { CT publicly } \\
\text { reported data }\end{array}$ & $\begin{array}{l}\text { No grade level data, } \\
\text { CT Only, School-level, } \\
\text { 2011/12-2018/19 }\end{array}$ & $\begin{array}{l}\text { Percent of students } \\
\text { missing more than } \\
10 \% \text { of school days }\end{array}$ & $\begin{array}{l}\text { Sandy Hook } \\
(2012 / 13)\end{array}$ & $\begin{array}{c}\text { Diff-in-Diff } \\
\text { (school, year) with } \\
\text { school-specific } \\
\text { trends }\end{array}$ \\
\hline $\begin{array}{l}\text { Educational } \\
\text { Expenditures }\end{array}$ & $\begin{array}{l}\text { Common Core of } \\
\text { Data }\end{array}$ & $\begin{array}{c}\text { No grade level data, } \\
\text { National, District-level, } \\
\text { 1995-2016 }\end{array}$ & $\begin{array}{l}\text { Expenditures in } \\
\text { multiple categories }\end{array}$ & $\begin{array}{l}105 \text { shootings that } \\
\text { occurred between } \\
1998 \text { and } 2013\end{array}$ & $\begin{array}{l}\text { Diff-in-Diff } \\
\text { (district, year) } \\
\text { with district- } \\
\text { specific trends }\end{array}$ \\
\hline $\begin{array}{l}\text { Educational } \\
\text { Expenditures }\end{array}$ & $\begin{array}{c}\text { Common Core of } \\
\text { Data }\end{array}$ & $\begin{array}{l}\text { No grade level data, } \\
\text { Restricted to CT only, } \\
\text { District-level, } \\
\text { 1995-2016 }\end{array}$ & $\begin{array}{l}\text { Expenditures in } \\
\text { multiple categories }\end{array}$ & $\begin{array}{l}\text { Sandy Hook } \\
(2012 / 13)\end{array}$ & $\begin{array}{l}\text { Diff-in-Diff } \\
\text { (district, year) } \\
\text { with district- } \\
\text { specific trends }\end{array}$ \\
\hline Mortality & $\begin{array}{l}\text { Vital Statistics } \\
\text { Mortality }\end{array}$ & $\begin{array}{l}\text { Track birth cohorts } \\
\text { through age 29, } \\
\text { County-level data, } \\
\text { 1995-2017, by gender }\end{array}$ & $\begin{array}{c}\text { Death rates by cause } \\
\text { (internal vs. external: } \\
\text { homicide, suicide, } \\
\text { accident) } \\
\end{array}$ & Columbine (1999) & $\begin{array}{l}\text { Triple Difference } \\
\text { (county, cohort, } \\
\text { year) }\end{array}$ \\
\hline Mortality & $\begin{array}{l}\text { Vital Statistics } \\
\text { Mortality }\end{array}$ & $\begin{array}{l}\text { Track birth cohorts } \\
\text { through age 29, } \\
\text { County-level data, } \\
\text { 1995-2017, by gender }\end{array}$ & $\begin{array}{c}\text { Death rates by cause } \\
\text { (internal vs. external: } \\
\text { homicide, suicide, } \\
\text { accident) } \\
\end{array}$ & $\begin{array}{c}103 \text { shootings in } \\
\text { high schools } \\
\text { between } 1995 \text { and } \\
2012 . \\
\end{array}$ & $\begin{array}{l}\text { Triple Difference } \\
\text { (county, cohort, } \\
\text { year) }\end{array}$ \\
\hline
\end{tabular}


Table 2: The Impact of a School Shooting on Standardized Test Scores

\begin{tabular}{|c|c|c|c|c|c|c|}
\hline & \multicolumn{2}{|c|}{ All Students } & \multicolumn{2}{|c|}{ Boys } & \multicolumn{2}{|c|}{ Girls } \\
\hline & Math & ELA & Math & ELA & Math & ELA \\
\hline All shootings & $\begin{array}{c}0.035 \\
(0.028)\end{array}$ & $\begin{array}{c}0.031 \\
(0.027)\end{array}$ & $\begin{array}{c}0.019 \\
(0.027)\end{array}$ & $\begin{array}{c}0.016 \\
(0.035)\end{array}$ & $\begin{array}{c}0.044 \\
(0.030)\end{array}$ & $\begin{array}{c}0.042 \\
(0.026)\end{array}$ \\
\hline $\begin{array}{l}\text { More than } 1 \text { Death } \\
\text { (Sandy Hook) }\end{array}$ & $\begin{array}{l}-0.086 \\
(0.021)\end{array}$ & $\begin{array}{l}-0.046 \\
(0.013)\end{array}$ & $\begin{array}{c}-0.124 \\
(0.022)\end{array}$ & $\begin{array}{c}-0.086 \\
(0.014)\end{array}$ & $\begin{array}{l}-0.073 \\
(0.019)\end{array}$ & $\begin{array}{l}-0.039 \\
(0.014)\end{array}$ \\
\hline 1 death & $\begin{array}{c}0.038 \\
(0.029)\end{array}$ & $\begin{array}{c}0.033 \\
(0.027)\end{array}$ & $\begin{array}{c}0.023 \\
(0.027)\end{array}$ & $\begin{array}{c}0.018 \\
(0.036)\end{array}$ & $\begin{array}{c}0.047 \\
(0.032)\end{array}$ & $\begin{array}{c}0.043 \\
(0.027)\end{array}$ \\
\hline Mean of dep var & 0.003 & -0.006 & -0.002 & -0.118 & 0.013 & 0.112 \\
\hline $\mathrm{N}$ & 2,732 & 2,855 & 2,700 & 2,835 & 2,701 & 2,837 \\
\hline
\end{tabular}

Note: authors' calculations based on district-level standardized test scores between the 2008/09 and 2015/16 school years. Test scores are measured in standard deviations relative to a national cohort. Shootings are restricted to those occurring in elementary and middle schools during this time period. Differences in sample sizes arise because SEDA does not report test score average if less than 95 percent of the students take the exam. 
Table 3: The Impact of the Sandy Hook School Shooting on School-Level Outcomes

\begin{tabular}{lccc} 
& Math Proficiency Percentile & ELA Proficiency Percentile & Chronic Absenteeism \\
\hline Sandy Hook*Post & $\mathbf{- 2 6 . 3 8}$ & $\mathbf{- 6 . 3 3}$ & 3.39 \\
& $\mathbf{( 2 . 2 9 )}$ & $\mathbf{( 1 . 8 7 )}$ & $\mathbf{( 0 . 4 1 )}$ \\
Other Newtown Elementary*Post & $\mathbf{- 3 4 . 6 0}$ & $\mathbf{- 1 7 . 7 3}$ & $\mathbf{1 . 2 0}$ \\
& $\mathbf{( 2 . 2 1 )}$ & $\mathbf{( 1 . 7 9 )}$ & $\mathbf{( 0 . 4 2 )}$ \\
\hline Mean of Dependent Variable & 50.03 & 50.11 & 6.18 \\
Sample Size & 4,132 & 4,132 & 1,876 \\
\hline
\end{tabular}

Note: authors' calculations based on data from the state of Connecticut on school-level proficiency rates between the 2007/08 and 2017/18 school years and chronic absenteeism between the 2011/12 and 2017/18 school years. Proficiency percentiles are measured as the percentile of the school's proficiency rate on standardized tests within the state, grade, and year; chronic absenteeism is measured as a percentage of all students. Regressions include school fixed effects, year fixed effect, and schoolspecific linear trends. Test score results include grade-level fixed effects. Regressions are weighted by the number of test-takers at each school (test score results) or enrollment (chronic absenteeism results). Standard errors are clustered at the district level. 
Table 4: The Impact of School Shootings on School Expenditures

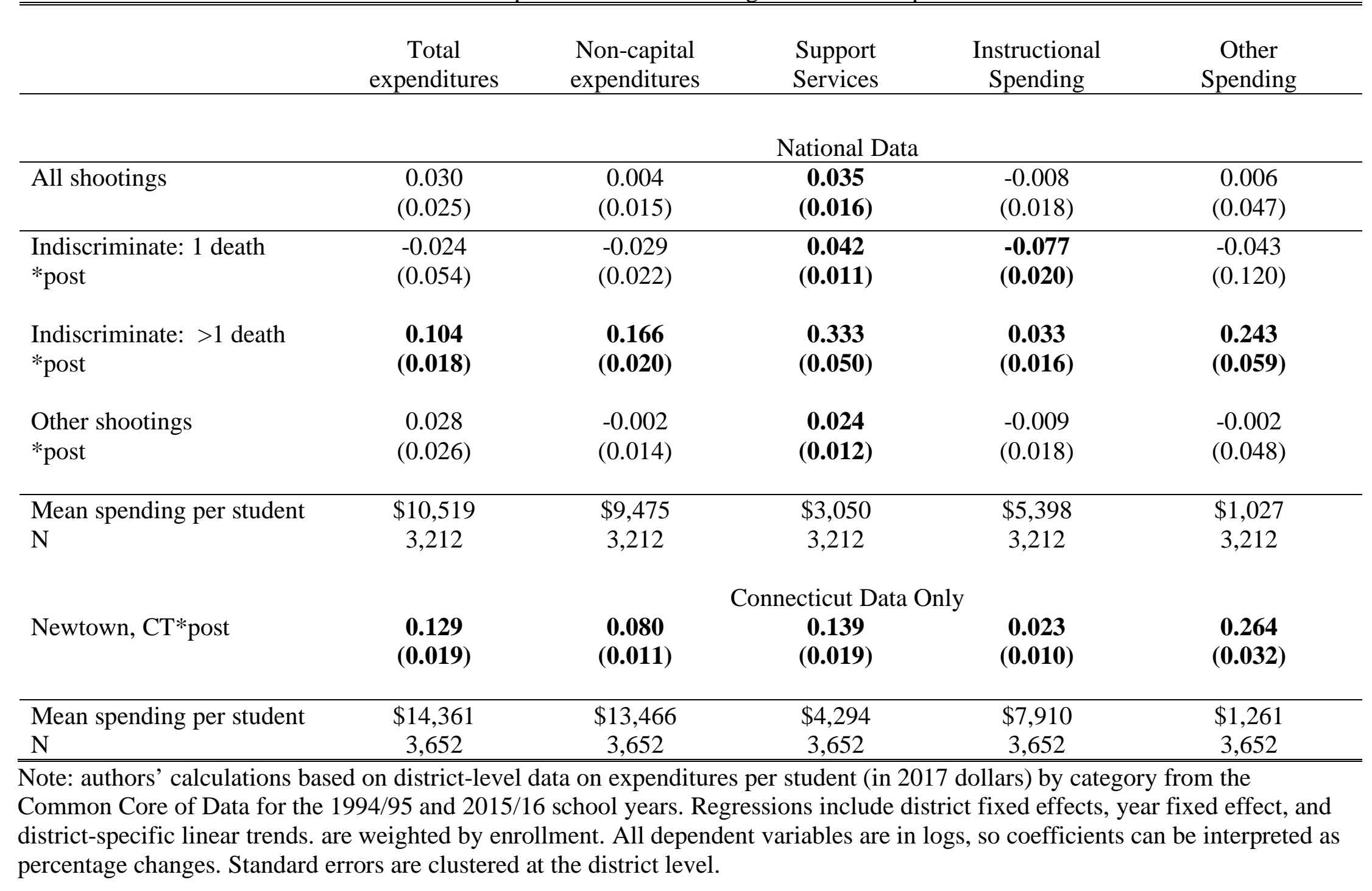


Table 5: Impact of Columbine Shooting on Mortality Rates by Gender

\begin{tabular}{|c|c|c|c|c|c|c|}
\hline & \multirow[b]{2}{*}{ All Deaths } & \multirow[b]{2}{*}{ External Deaths } & \multirow[b]{2}{*}{$\begin{array}{c}\text { Non-External } \\
\text { Deaths }\end{array}$} & \multicolumn{3}{|c|}{ Types of External Deaths } \\
\hline & & & & Homicide & Suicide & $\begin{array}{c}\text { Accidental } \\
\text { Deaths }\end{array}$ \\
\hline & \multicolumn{6}{|c|}{ Male } \\
\hline Contemporaneous Impact & $\begin{array}{c}0.960 \\
(0.117)\end{array}$ & $\begin{array}{c}0.962 \\
(0.100)\end{array}$ & $\begin{array}{l}-0.177 \\
(0.022)\end{array}$ & $\begin{array}{c}0.487 \\
(0.046)\end{array}$ & $\begin{array}{c}0.194 \\
(\mathbf{0 . 0 3 6 )}\end{array}$ & $\begin{array}{c}0.022 \\
(0.034)\end{array}$ \\
\hline \multirow[t]{2}{*}{ Subsequent Impact } & $\begin{array}{c}0.036 \\
(0.032)\end{array}$ & $\begin{array}{c}0.044 \\
(0.023)\end{array}$ & $\begin{array}{l}-0.012 \\
(0.012)\end{array}$ & $\begin{array}{l}-0.039 \\
(0.007)\end{array}$ & $\begin{array}{c}0.038 \\
(0.010)\end{array}$ & $\begin{array}{c}0.034 \\
(0.011)\end{array}$ \\
\hline & \multicolumn{6}{|c|}{ Female } \\
\hline Contemporaneous Impact & $\begin{array}{l}-0.234 \\
(0.072)\end{array}$ & $\begin{array}{c}0.027 \\
(0.071)\end{array}$ & $\begin{array}{r}-0.119 \\
(0.044)\end{array}$ & $\begin{array}{c}0.250 \\
(0.012)\end{array}$ & $\begin{array}{l}-0.066 \\
(0.030)\end{array}$ & $\begin{array}{c}0.029 \\
(0.021)\end{array}$ \\
\hline Subsequent Impact & $\begin{array}{c}0.082 \\
(0.033)\end{array}$ & $\begin{array}{c}0.030 \\
(0.025)\end{array}$ & $\begin{array}{l}-0.015 \\
(0.011)\end{array}$ & $\begin{array}{l}0.016 \\
(0.004)\end{array}$ & $\begin{array}{l}-0.020 \\
(0.009)\end{array}$ & $\begin{array}{l}-0.012 \\
(0.011)\end{array}$ \\
\hline
\end{tabular}

Note: authors' calculations based on county-level Vital Statistics mortality data from Colorado between 1995 and 2017. Columbine High School is part of the Jefferson County School District. To convert these results into the impact on number of deaths, the coefficients need to be multiplied by cohort size in 1,000s. These values for boys and girls in Jefferson County is 19.9 and 18.4, respectively. 
Table 6A: Impact of School Shootings on Mortality Rates for Boys

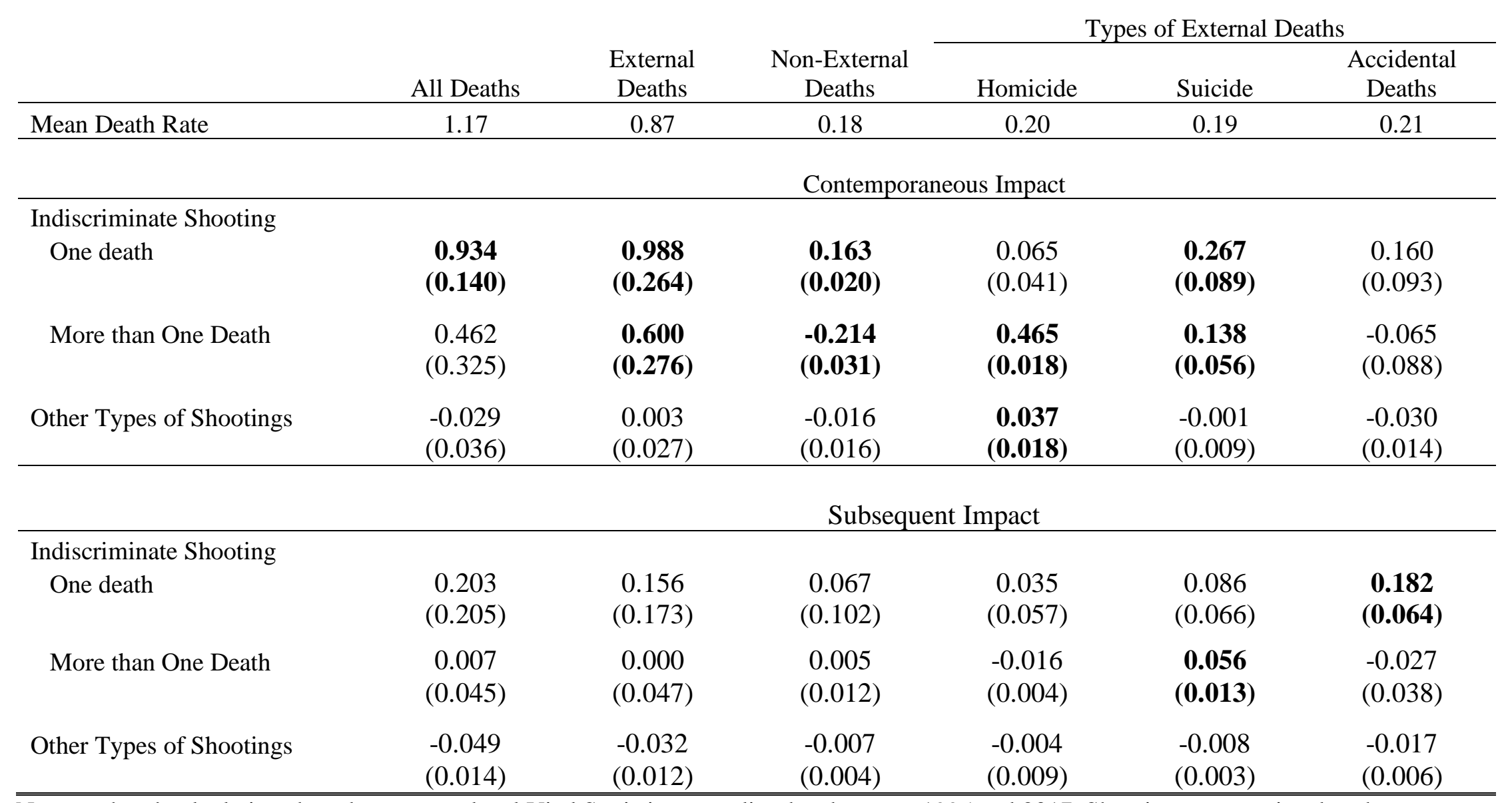

Note: authors' calculations based on county-level Vital Statistics mortality data between 1995 and 2017. Shootings are restricted to those occurring in high schools and between 1995 and 2012. To convert these results into the impact on number of deaths, the coefficients need to be multiplied by cohort size in 1,000s. These values are 1.9 for those exposed to an indiscriminate shooting with one death, 7.1 for those exposed to an indiscriminate shooting with more than one death, and 41.9 for all other shootings. 
Table 6B: Impact of School Shootings on Mortality Rates for Girls

\begin{tabular}{|c|c|c|c|c|c|c|}
\hline & \multirow[b]{2}{*}{ All Deaths } & \multirow[b]{2}{*}{$\begin{array}{l}\text { External } \\
\text { Deaths }\end{array}$} & \multirow[b]{2}{*}{$\begin{array}{l}\text { Non-External } \\
\text { Deaths }\end{array}$} & \multicolumn{3}{|c|}{ Types of External Deaths } \\
\hline & & & & Homicide & Suicide & $\begin{array}{l}\text { Accidental } \\
\text { Deaths }\end{array}$ \\
\hline Mean Rate & 0.46 & 0.25 & 0.13 & 0.04 & 0.04 & 0.06 \\
\hline & \multicolumn{6}{|c|}{ Contemporaneous Impact } \\
\hline \multicolumn{7}{|l|}{ Indiscriminate Shooting } \\
\hline One death & $\begin{array}{c}-0.241 \\
(0.114)\end{array}$ & $\begin{array}{c}0.017 \\
(0.027)\end{array}$ & $\begin{array}{r}-0.146 \\
(0.037)\end{array}$ & $\begin{array}{l}-0.004 \\
(0.013)\end{array}$ & $\begin{array}{c}0.012 \\
(0.025)\end{array}$ & $\begin{array}{c}0.060 \\
(0.011)\end{array}$ \\
\hline More than One Death & $\begin{array}{c}0.172 \\
(0.228)\end{array}$ & $\begin{array}{c}0.384 \\
(0.252)\end{array}$ & $\begin{array}{c}-0.115 \\
(0.087)\end{array}$ & $\begin{array}{c}0.401 \\
(0.195)\end{array}$ & $\begin{array}{c}0.040 \\
(0.082)\end{array}$ & $\begin{array}{c}0.040 \\
(0.009)\end{array}$ \\
\hline Other Types of Shootings & $\begin{array}{l}-0.047 \\
(0.024)\end{array}$ & $\begin{array}{l}-0.024 \\
(0.018)\end{array}$ & $\begin{array}{l}-0.010 \\
(0.008)\end{array}$ & $\begin{array}{c}0.006 \\
(0.006)\end{array}$ & $\begin{array}{l}-0.004 \\
(0.005)\end{array}$ & $\begin{array}{l}-0.009 \\
(0.008)\end{array}$ \\
\hline & \multicolumn{6}{|c|}{ Subsequent Impact } \\
\hline \multicolumn{7}{|l|}{ Indiscriminate Shooting } \\
\hline One death & $\begin{array}{c}0.092 \\
(0.107)\end{array}$ & $\begin{array}{c}0.125 \\
(0.073)\end{array}$ & $\begin{array}{c}0.026 \\
(0.026)\end{array}$ & $\begin{array}{c}0.008 \\
(0.002)\end{array}$ & $\begin{array}{c}0.063 \\
(0.068)\end{array}$ & $\begin{array}{c}0.073 \\
(0.030)\end{array}$ \\
\hline More than One Death & $\begin{array}{c}0.038 \\
(0.060)\end{array}$ & $\begin{array}{c}0.022 \\
(0.030)\end{array}$ & $\begin{array}{c}-0.018 \\
(0.013)\end{array}$ & $\begin{array}{c}0.011 \\
(0.009)\end{array}$ & $\begin{array}{c}-0.001 \\
(0.003)\end{array}$ & $\begin{array}{l}-0.003 \\
(0.010)\end{array}$ \\
\hline Other Types of Shootings & $\begin{array}{c}-0.024 \\
(0.006)\end{array}$ & $\begin{array}{l}-0.013 \\
(0.005)\end{array}$ & $\begin{array}{c}-0.007 \\
(0.003)\end{array}$ & $\begin{array}{c}-0.002 \\
(0.002)\end{array}$ & $\begin{array}{c}-0.002 \\
(0.001)\end{array}$ & $\begin{array}{l}-0.005 \\
(0.003)\end{array}$ \\
\hline
\end{tabular}

Note: authors' calculations based on county-level Vital Statistics mortality data between 1995 and 2017. Shootings are restricted to those occurring in high schools and between 1995 and 2012. To convert these results into the impact on number of deaths, the coefficients need to be multiplied by cohort size in 1,000s. These values are 1.8 for those exposed to an indiscriminate shooting with one death, 6.5 for those exposed to an indiscriminate shooting with more than one death, and 40.4 for all other shootings. 